\title{
Reflections about palliative care for people with severe dementia
}

\section{Carmen Sarabia-Cobo* \\ Department of Nursing, University of Cantabria, Cantabria, Spain}

Approaches to palliative care (PC) that were originally developed for people with cancer are now being adopted for people with dementia, as a response to many reports of poor-quality care for people with dementia at the end of life $[1,2]$. Currently there are no curative treatments for dementia, so as recommended by the World Health Organization, the PC should be applied from the earliest stages of chronic and fatal disease [3].

Dementia is a syndrome characterized by a progressive decline in memory and cognitive functioning, and it is recognized as a major health problem in the elderly [4]. For these patients, early access to CP improves quality of life and may even prolong life [5].

Whilst PC for cancer has long been established, PC for people with dementia is only just beginning to develop and be accepted across Europe and beyond [6]. Many of the needs in end-stage dementia are similar to those with cancer, including shortness of breath, skin breakdown, infections and constipation $[7,8]$, but in dementia these symptoms can be experienced for a prolonged period of time. Until recent publication of the EAPC White Paper on PC in dementia [9], there was relatively little guidance on the provision of PC for this patient group [10-12].

Several studies have explored the barriers to the delivery of quality PC for people with dementia $[13,14]$. One barrier is that dementia is often not recognized as a 'terminal' illness requiring palliation. In addition, the course of dementia is unpredictable, making it difficult to reach an accurate prognosis. Communicating with patients and families of people with dementia requires special skills because the cognitive problems associated with dementia complicate decision making around a host of issues.

The different courses of patient deterioration warrant dementiaspecific PC strategies. The EAPC White Paper recommends paying special attention to eight areas of care including communication, person-centred care and optimal treatment of symptoms and providing comfort [9].

PC for patients with advanced or terminal dementia should be improved in relation to the PC in cancer processes [15]. Such highquality evidence is not yet available for PC in dementia, although dementia care at the end of life is increasingly being studied $[16,17]$.

There is a need to improve palliative care provision for elderly with end-stage dementia and, in addition, more research is required on the needs of patients entering the terminal phase of dementia. By the nurses decisions about PC en advance dementia need to be made about how patients live, as well as how they die, thus balancing quality of living/comfort with disease management.

\section{References}

1. Dening KH (2016) Palliative and end of life care for people with dementia. Nursing Standard 30: 42-49.

2. Dempsey L, Dowling M, Larkin P, Murphy K (2015) The unmet palliative care needs of those dying with dementia. Int J Palliat Nurs 21: 126-133. [Crossref]

3. World Health Organization (2002) Definition of palliative care.

4. Prince M, Bryce R, Albanese E, Wimo A, Ribeiro W, et al. (2013) The globa prevalence of dementia: a systematic review and metaanalysis. Alzheimers Dement 9 : 63-75. [Crossref]

5. Lawrence V, Samsi K, Murray J, Harari D, Banerjee S (2011) Dying well with dementia: qualitative examination of end-of-life care. Br J Psychiatry 199: 417-422. [Crossref]

6. Nakanishi M, Nakashima T, Shindo Y, Miyamoto Y, Gove D, et al. (2015) An evaluation of palliative care contents in national dementia strategies in reference to the European Association for Palliative Care white paper. Int Psychogeriatr 27: 15511561. [Crossref]

7. Davies N, Maio L, van Riet Paap J, Mariani E, Jaspers B, et al. (2014) Quality palliative care for cancer and dementia in five European countries: some common challenges. Aging Ment Health 18: 400-410. [Crossref]

8. Goodman C, Amador S, Elmore N, Machen I, Mathie E (2013) Preferences and priorities for ongoing and end-of-life care: A qualitative study of older people with dementia resident in care homes. International Journal of Nursing Studies 50: 16391647.

9. van der Steen JT, Radbruch L, Hertogh CM, de Boer ME, Hughes JC, et al. (2013) White paper defining optimal palliative care in older people with dementia: a Delphi study and recommendations from the European Association for Palliative Care Palliative Medicine.

10. Iliffe S, Davies N, Vernooij-Dassen M, van Riet Paap J, Sommerbakk R, et al. (2013) Modelling the landscape of palliative care for people with dementia: a European mixed methods study. BMC Palliat Care 12: 30. [Crossref]

11. National Council for Palliative Care (NCPC) (2009) Out of the shadows: end of life care for people with dementia. London: National Council for Palliative Care (NCPC).

12. Ryan T, Gardiner C, Bellamy G, Gott M, Ingleton C (2012) Barriers and facilitators to the receipt of palliative care for people with dementia: the views of medical and nursing staff. Palliat Med 26: 879-886. [Crossref]

13. Davies N, Maio L, van Riet Paap J, Mariani E, Jaspers B, et al. (2014) Quality palliative care for cancer and dementia in five European countries: some common challenges. Aging Ment Health 18: 400-410. [Crossref]

14. Harrison-Dening K, Greenish W, Jones L, Mandal U, Sampson EL (2012) Barriers to providing end-of-life care for people with dementia: a whole-system qualitative study. BMJ Supportive and Palliative Care 2: 103-107.

Correspondence to: Carmen Sarabia-Cobo, ( $\mathrm{PhD}, \mathrm{RN}, \mathrm{MSN})$, Department of Nursing, University of Cantabria, Spain, Tel: +34942202293; E-mail: carmen.sarabia@unican.es

Received: February 28, 2016; Accepted: March 21, 2016; Published: March 25, 2016 
15. Brodaty H, Seeher K, Gibson L (2012) Dementia time to death: a systematic literature review on survival time and years of life lost in people with dementia. Int Psychogeriatr 24: 1034-1045. [Crossref]

16. Sampson EL, Burns A, Richards M (2011) Improving end-of-life care for people with dementia. Br J Psychiatry 199: 357-359. [Crossref]
17. Davies N, Maio L, Vedavanam K, Manthorpe J, Vernooij-Dassen M, et al. (2013) Barriers to the provision of high-quality palliative care for people with dementia in England: a qualitative study of professionals' experiences. Health \& Social Care in the Community 22: 386-394

Copyright: (C2016 Sarabia-Cobo C. This is an open-access article distributed under the terms of the Creative Commons Attribution License, which permits unrestricted use, distribution, and reproduction in any medium, provided the original author and source are credited. 